\title{
Multi-band Circularly Polarized Microstrip Antenna for Wireless Communication
}

\author{
Manisha Gupta \\ Dept. ECE \\ ABES Engineering College Ghaziabad, UP, India
}

\author{
Himani Garg \\ Dept. ECE \\ ABES Engineering College Ghaziabad, UP, India
}

\begin{abstract}
The paper presents a compact monopole antenna with an integrated circularly polarized band for wireless communication. The proposed monopole antenna having a defected ground structure which uses two L-shaped slots of equal size and an unsymmetrical slot of inverted E-shaped. These slots in the ground patch are used for achieving dual band notching. The radiating patch is embedded with a staircase rectangular shape radiator( i.e. two equal square slots are detached from the lower corners). This radiating patch is used to generate the two current modes in 90 degree phase deviation and approximately equal magnitude by which circularly polarized radiation is generated. The measured results show that the proposed dual polarized monopole antenna offers a very high gain with $10 \mathrm{db}$ return loss and multi notched bands, covering all the (3.1-3.5) GHz WiMAX, (5.07-6.05) GHz WLAN, (6.75-8.95) GHz X bands, (3.5-5.07) GHz C-band for satellite application.
\end{abstract}

\section{Keywords}

Multi-band notches; dual polarization; L-shaped slot; staircase shaped patch; microstrip feeding; ultra-wideband

\section{INTRODUCTION}

In the present time, many wireless services provider like to use polarization diversity and frequency diversity in the place of space diversity to take the advantages of the limited frequency spectra which are available for communication. In the polarization and frequency diversity, the single antenna is capable to generate multiple frequencies with the multiple polarization. Multiple frequencies with the multiple polarization antennas increases the system capacity. Circularly polarized antennas are mostly used in portable handheld devices such as WLAN, RFID reader, GPS, satellite communication etc. whenever linear polarized antenna are used for transmitting and receiving radio wave of same polarization. So with the increase of application in wireless communications, circularly polarized antenna has become highly desirable.

In the recent past, researchers have been giving a lot of attention to wide band antennas. A number of shape of slits or slots are used to generate the multi-notches circularly polarisation reported in the previously published literature. A single feed dual band and dual polarization antenna for Aeronautical and Radio application is proposed in[1]. The antenna consist a back to back patch and two shapes(spiral and dumbbell shape) in the ground plane. Dumbbell shape is used to improve the impedance matching and spiral shape is used to generate the circular polarization. A Planer Monopole Antenna with Dual Interference Suppression Functionality is proposed in[2]. The antenna consists of an angular ring radiating patch with $\mathrm{Y}$ Shaped resonant element placed inside the patch to generate circular polarization. The ground consists a trapezoidal structure and a U-Shaped slit on the upper side of a trapezoidal structure for the generation of multi-band notches. A Tri-band microstrip feed antenna with dual polarization for WLAN and WiMAX application is proposed [3]. The antenna consist a partial ground and a Y-Shaped radiating patch having two unequal monopole arms and a modified circle monopole to generate three separate impedance bandwidth and circular polarization. A slotted ground microstrip antenna with FSS(frequency selective surface)is proposed in[4]. FSS is two layer structure where each layer used as a array of rectangular patches embedded on the one side of substrate. The patch slot and feed line both are three stepped used to get wide bandwidth. The ground planed also contain a slot to generate dual polarization. The antenna proposed in [5] has a stacked patch structure in which the upper patch is a corner truncated square patch fed directly by a probe which generates circular polarization. The antenna proposed in [6] consist Z- shaped cylindrical dielectric resonator antenna(CDRA) along with dual C- shaped patch. Offset between upper and lower CDRAs generates circular polarization. In [7] circular polarization is generates by adding a pair of open stubs in the inner boundary of the angular ring of the patch. The antenna proposed in [8] comprises an $\mathrm{H}$ - shaped microstrip patch over a meta-material inspired reactive impedance surface (RISC) to generate circular polarization. An unobtrusive single fed meta-material loaded patch antenna is proposed in [9]. This antenna is consisting of mushroom like composite right/left handed resonator for exciting circular polarization. Single feed techniques provide very narrow axial ratio bandwidth so to broaden the bandwidth a dual fed proximity coupled L-shape cavity backed structure is proposed in [10]. This type of ground surface is used to improve the feed coupling consequently to widen the antenna bandwidth. CP can also be achieved by parasitic loading [11] or by inserting stubs [12]. Dual band CP operation is realized by introducing a parasitic patch under the radiating patch in [11] whereas in [12] L-shaped stubs are loaded exterior to the trimmed patch so that outer and inner mode can be excited. By introducing asymmetrical slits on each corner of square patch circular polarization is achieved in [13-14]. For size reduction and to acquire circular polarization arrowhead shaped slotted antenna is proposed in reference [15].

In this paper, a multifunction monopole antenna with multifrequency band and circular polarization is designed. A pair of L-shaped slots is placed on the partial ground, to get wide bandwidth. An unsymmetrical slot of inverted E- shaped in which middle arm is smaller than others two arm is placed on the upper side of partial ground which is used to generate the multi-band notches. Circular polarisation is generate by the staircase shaped with modified shape of E -slot. The antenna is single feed. Ansys HFSS tool is used for the simulation and development of antenna. 


\section{ANTENNA DESIGN}

Figure 1 represented the schematic configuration of designing of the antenna. The designed antenna is printed on an FR4 substrate of height $1 \mathrm{~mm}$ and dielectric permittivity 4.4 . The basic antenna structure consists of a rectangular radiating patch, a single feed line, and a partial ground plane. On the front side of substrate the patch is connected to a feed line, as shown in figure1(a). On the back side of the substrate, a partial conducting ground plane(LG×WG) and E and L shaped slots are placed .

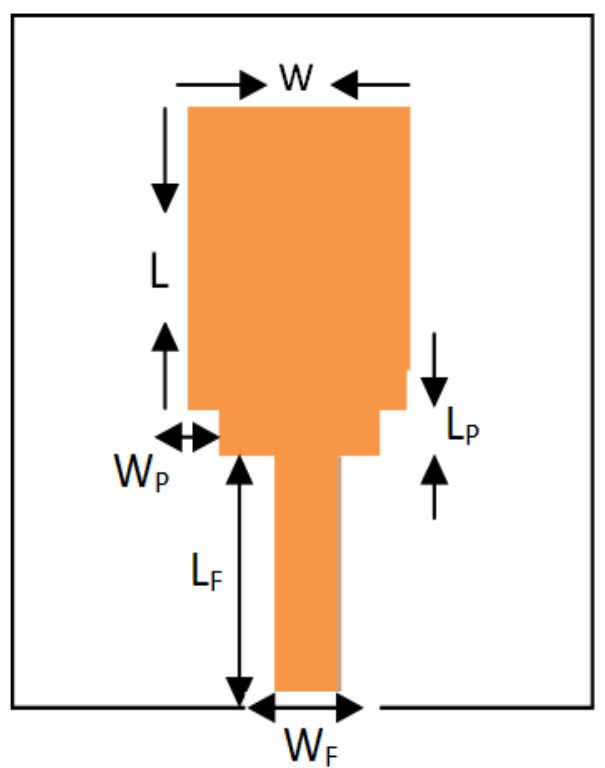

(a)

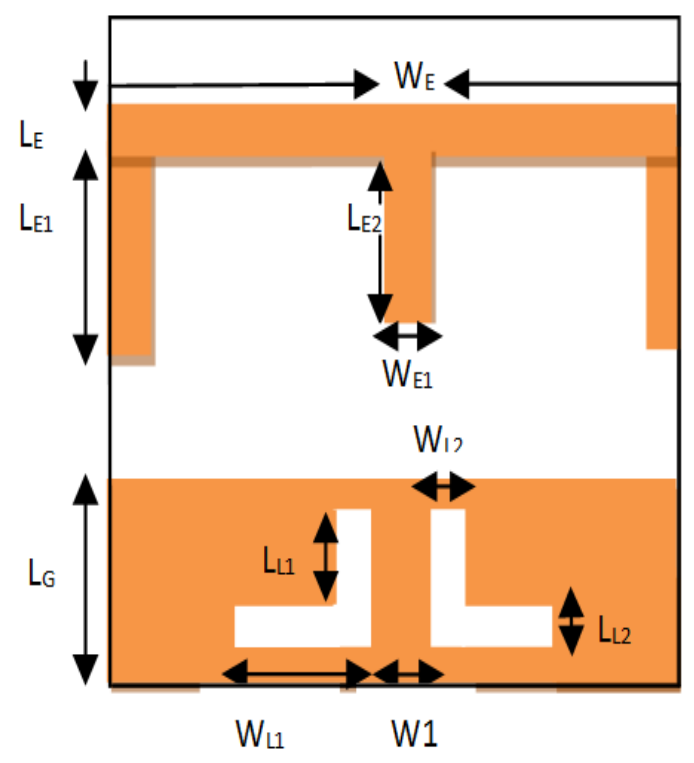

(b)

Fig 1: Geometry of the proposed multi band-notched UWB antenna: (a) front side of the substrate; (b) back side of the substrate
Table 1. Parameters of the designed antenna

\begin{tabular}{|c|c|c|c|}
\hline Dimension & $\mathrm{mm}$ & Dimension & $\mathrm{mm}$ \\
\hline $\mathrm{W}_{\mathrm{SUB}}$ & 22 & $\mathrm{~L}_{\mathrm{SUB}}$ & 24 \\
\hline $\mathrm{W}$ & 10 & $\mathrm{~L}$ & 13 \\
\hline $\mathrm{W}_{\mathrm{P}}$ & 1 & $\mathrm{~L}_{\mathrm{P}}$ & 2 \\
\hline $\mathrm{W}_{\mathrm{F}}$ & 1.9 & $\mathrm{~L}_{\mathrm{F}}$ & 8 \\
\hline $\mathrm{W}_{\mathrm{E}}$ & 22 & $\mathrm{~L}_{\mathrm{E}}$ & 0.8 \\
\hline $\mathrm{W}_{\mathrm{E} 1}$ & 0.8 & $\mathrm{~L}_{\mathrm{E} 1}$ & 8.2 \\
\hline $\mathrm{W}_{\mathrm{L} 1}$ & 6.45 & $\mathrm{~L}_{\mathrm{L} 1}$ & 1.4 \\
\hline $\mathrm{W}_{\mathrm{L} 2}$ & 0.8 & $\mathrm{~L}_{\mathrm{L} 2}$ & 0.8 \\
\hline $\mathrm{W}_{1}$ & 1.9 & $\mathrm{~L}_{\mathrm{G}}$ & 6 \\
\hline $\mathrm{L}_{\mathrm{E} 2}$ & 7.2 & & \\
\hline
\end{tabular}

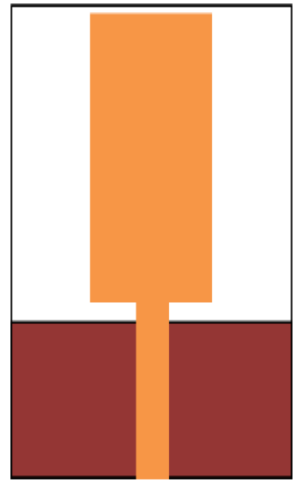

(a)

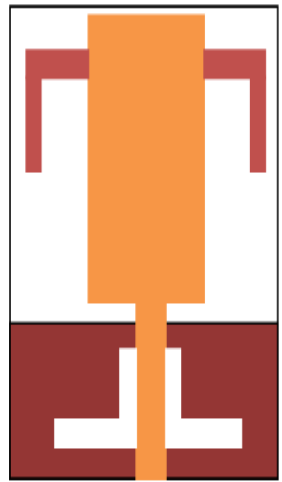

(b)

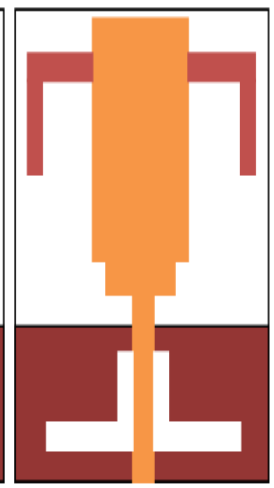

(c)
Fig 2: Designing steps (a) ordinary rectangular antenna (b) antenna with defected ground plane (c) proposed antenna

Figure 2 shows the steps followed in designing the structure of the antenna. Initially, a simple rectangular radiating patch with microstrip line feed and a partial ground plane is etched which generates a single bandwidth. After this, two L-shaped slots of equal size are placed in a partially modified ground plane, to achieve a wide bandwidth. The L-slot consists of one horizontal arm and one vertical arm of different dimensions connected at their ends. On the upper side of the partial ground an unsymmetrical slot of inverted E- shaped in which middle arm is smaller than others two arm is placed. Due to this E- shaped slot, multi-band notches are achieved. The position of higher and lower frequency of the multi-bands have affected by the small changes in the three arm of E- shape. The radiating patch is etched with a staircase rectangular shape radiator( i.e. two equal square slots are detached from the lower corners). This radiating patch is used to generate the two current modes in 90 degree phase deviation and approximately equal magnitude by which circularly polarized radiation is generated. For getting circular polarization at $3.24 \mathrm{GHz}$ frequency two equal square slots are detached from the lower corners of the rectangular patch. The desirable axial ratio can also be improved by changing the length and the width of the E- shape slot. 


\section{RESULT AND DISCUSSION}

Here, the result of the proposed antenna are discussed and presenting.

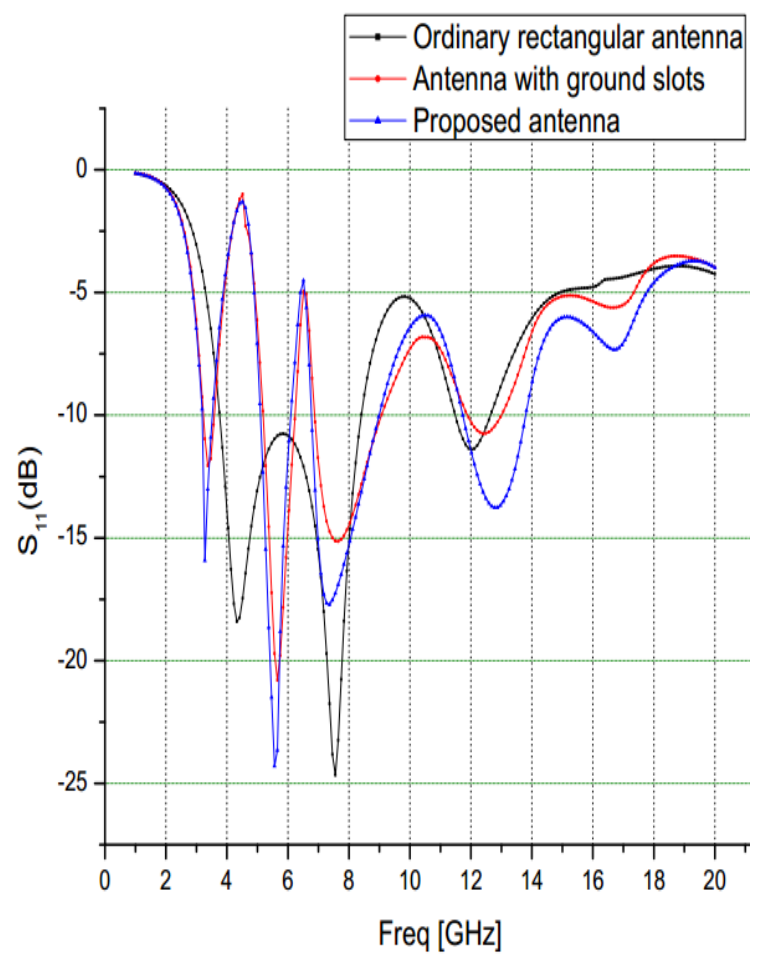

Fig 3: $S_{11}$ Characteristics of antenna desinning steps (in Fig.1)

Figure 3 shows the deflection in return loss with frequency for single rectangular radiator(figure 2(a)), antenna with deflected ground (figure 2(b)) and antenna with staircase shaped patch(figure2(c)). The antenna of single rectangular radiator and partial ground gives the frequency spectrum of 3.7-8.4 GHz. Afterwards, two equal L- shaped slots in partial ground and an unsymmetrical slot of inverted E- shaped are loaded in ground for converting wide band antenna into multi band radiator (3$3.7 \mathrm{GHz}, \quad 5.03-6.3 \mathrm{GHz}, 6.7-9.8 \mathrm{GHz}$ and $11.06-13.7 \mathrm{GHz}$ ) by introducing band elimination notches. when we use the staircase shaped patch instead of the rectangular patch the proposed antenna becomes dual polarized that means radiates both linear and circular polarized waves. To get impedance matching for the SMA conductor, the antenna is fed up by microstrip feeding technique.

The S11 variation of proposed antenna is shown in fig. 4. The antenna resonates for $3.1-3.5 \mathrm{GHz}, 5.07-6.05 \mathrm{GHz}, 6.75-8.95 \mathrm{GHz}$ and $11.68-13.77 \mathrm{GHz}$ with band elimination notches between $3.5-5.07 \mathrm{GHz}, 6.05-6.75 \mathrm{GHz}$ and $8.95-11.68 \mathrm{GHz}$. The multiple bands covers the (3.1-3.5) GHz- WiMAX , (5.07-6.05)GHzWLAN, (6.75-8.95)GHz-X BAND applications. It also gives the bands used for the satellite application( 3.5-5.07)GHz-C-band downlink. The overall $10-\mathrm{dB}$ return loss bandwidth ranges from 3.1 to more than $13.78 \mathrm{GHz}$.

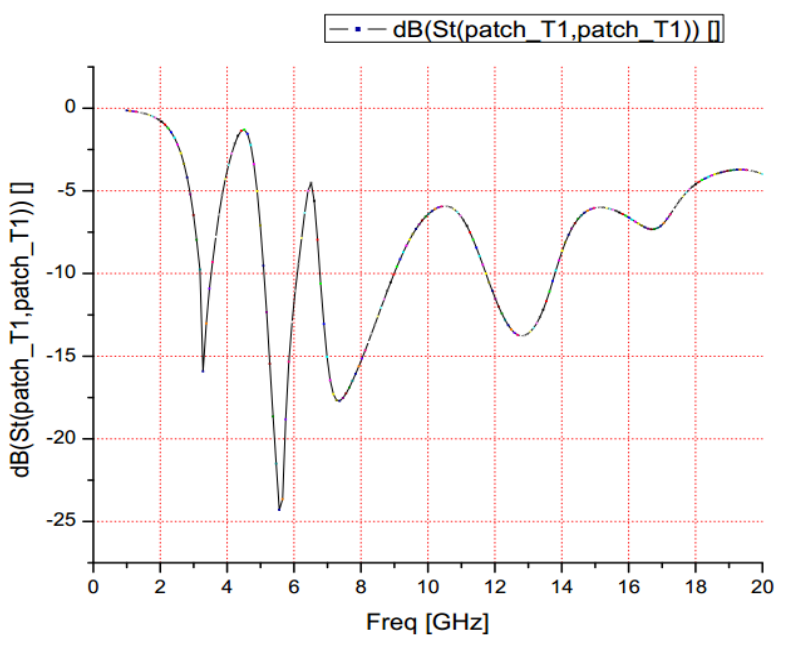

Fig 4: Simulated return losses

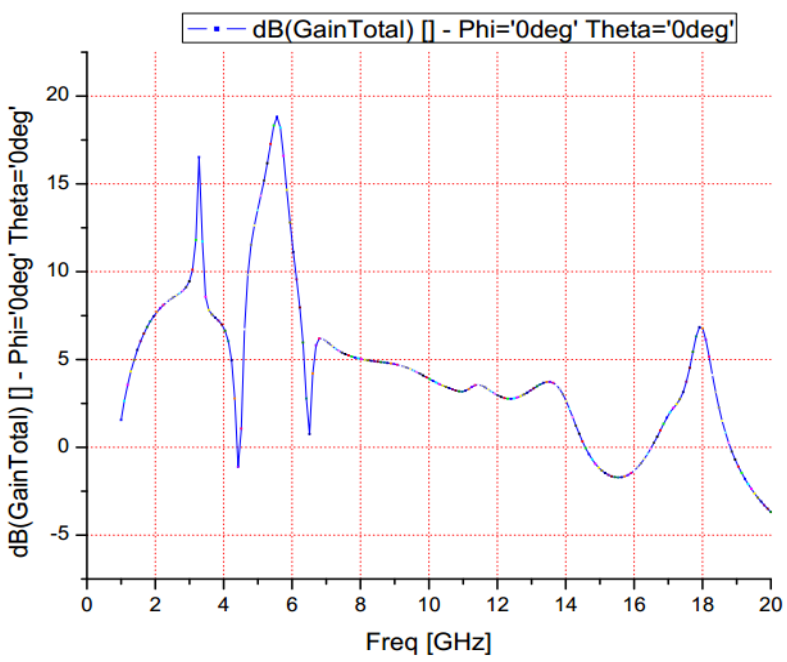

Fig 5: Simulated gain

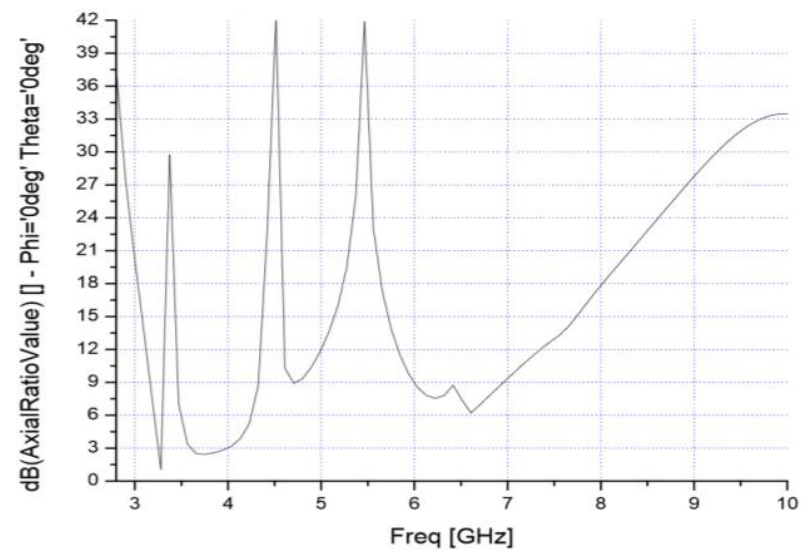

Fig 6: Axial ratio

Figure 5 shows the deviation of peak gain and frequency. The gain characteristic also shows the non responsive behavior at the notch bands. Figure 6 shows the axial ratio characteristic of the proposed antenna. The designed antenna is able to achieve the circular polarization at $3.24 \mathrm{GHz}$. Therefore this antenna works for WLAN application. Figure 7 shows the radiation pattern of the designed antenna at $3.24 \mathrm{GHz}$ frequency. The main purpose 
of the radiation patterns is to express that the antenna really radiates over a wide frequency band.

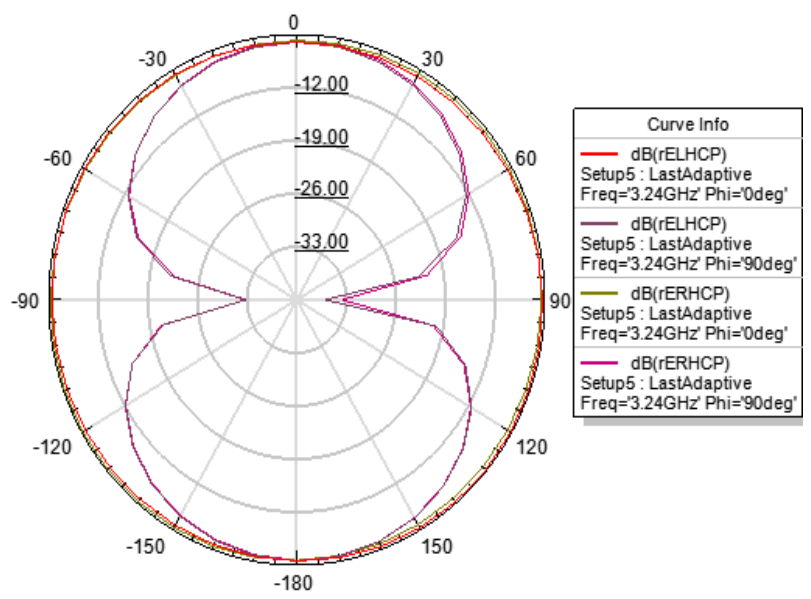

Fig 7: Radiation pattern at frequency $3.24 \mathrm{GHz}$

\section{FABRICATION AND RESULT}

The dual-polarized micro-strip patch antenna in design 8 was fabricated and tested by Scalar Network Analyzer. The substrate material is FR4 with $\mathrm{Er}=3.2$ and $\tan \delta=0.014$ with thickness $1 \mathrm{~mm}$.

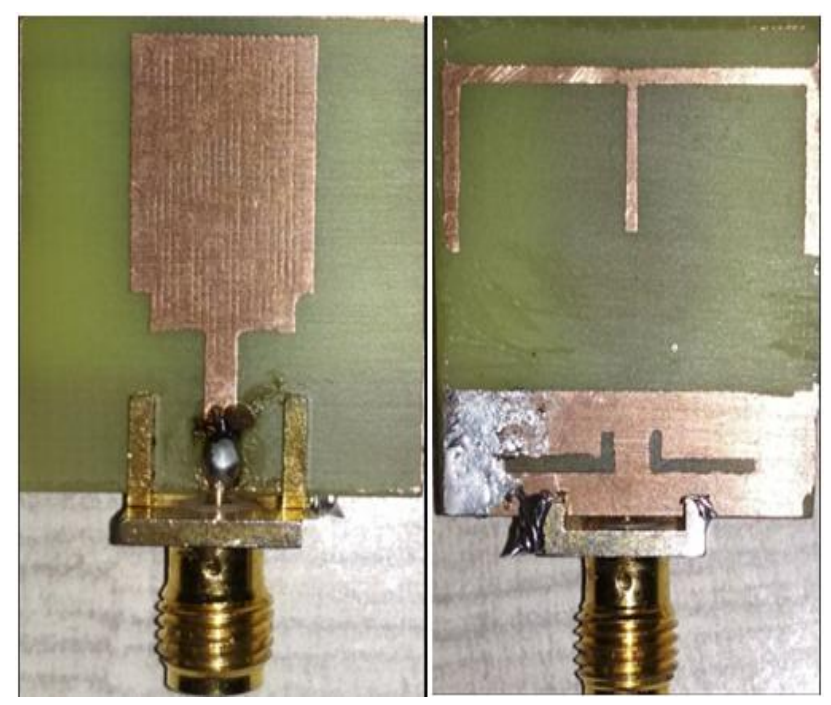

Fig 8: Fabricated Antenna

The return loss of the fabricated antenna shows a slight shift in the frequencies which could be due to fabrications errors and meshing of the simulated structure. Now we get multiple bands in which radiate notches frequencies are $3.1 \mathrm{GHz}, 4.95 \mathrm{GHz}$, $5.4 \mathrm{GHz}, 6.27 \mathrm{GHz}, 7.67 \mathrm{GHz}$ and $9.27 \mathrm{GHz}$. The bandwidth is $2.7 \mathrm{GHz}$ to $10 \mathrm{GHZ}$.

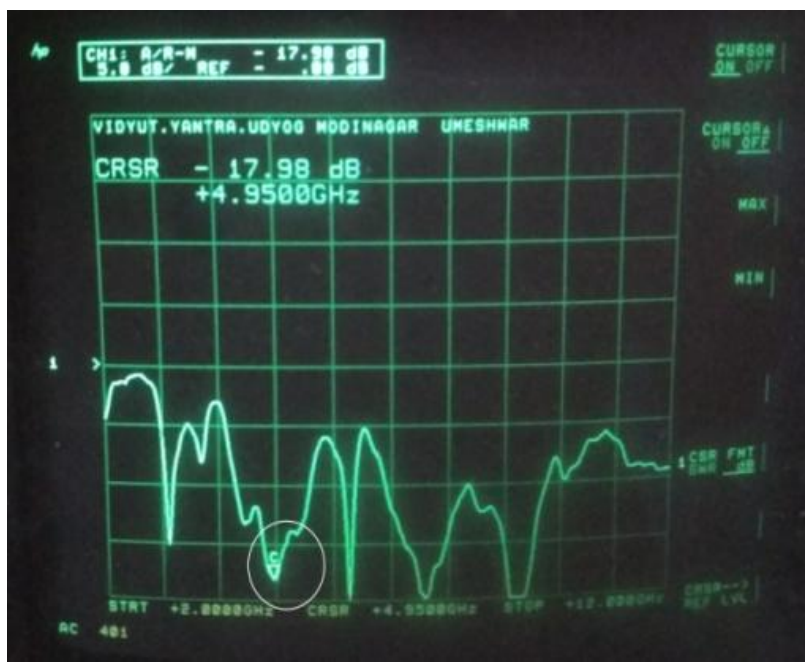

Fig 9: Return Loss of fabricated antenna shows notch $17.99 \mathrm{~dB}$ at $4.95 \mathrm{GHz}$

\section{CONCLUSION}

In this paper, a multi-function novel compact ultra-wideband planar monopole antenna with multi band notched characteristics has been proposed for numerous applications. The fabricated antenna has the frequency band from 3.1 to $13.7 \mathrm{GHz}$ and above with three rejection bands around 3.5-5.05, 6.05-6.73 GHz, and 8.9-11.68 GHz. By etching different type of slots like L-shape and E-shape, antenna shows the different characteristics. Truncation of two squares from the rectangular radiator produce quadrature current modes required for circular polarisation. The proposed antenna has a simple configuration and is easy to fabricate. Experimental results show that the proposed antenna is highly suited to today's system which uses both long and shorter distance communications.

\section{REFERENCES}

[1] R.S. Aziz, M.A.S. Alkanhal and A.F.A. Sheta," Multiband Fractal- like antenna. Progess in Electromagnetic Research", Vol.29, 339-354. 2011

[2] R. Karimian, H. Oraizi, S. Fakhte," Design of a compact ultra-wide-band monopole antenna with wideband rejection characteristics". IET Microwave, Antenna and Propogation, Vol.8, ISS. 8, PP.604-610. 2014

[3] P.R. Prajapati, A. Patnaik and M.V. Kartikeyan," Design of Single Feed Dual Band Polarisation Microstrip Antenna with Defected Ground Structure for Aeronautical and Radio Naviagation Application". 978-1-4673-5225-3/14/\$31.00 (C)2014 IEEE.

[4] R.V.S. Ram Krishna and R. Kumar," Slotted ground microstrip antenna with FSS reflector for high gain horizontal polarisation". Electronics Letters Vol. 51 No.8 PP.599-600. 2015

[5] Xiao-Qi Zhu, Yong-Xin Guo and Wen Wu," Miniturized Dual-Band and Dual-Polarized antenna for MBAN application.", IEEE Transactions on Antennas and Propagation, DOI 10.1109/TAP.2016.2556701.

[6] Anand Sharma and Ravi Kumar Gangwar,"Circularly Polarised Hybrid Z- shaped cylindrical dielectric resonator antenna for multi-band application", IET Microwave, Antenna and Propogation, ISSN 1751-8725, DOI 10.1049/iet-map.2016.0035 
[7] Rong Qiang Li, Yong-Xin Guo, Bing Zhang and Ghohong $\mathrm{Du}$, "A Miniturized Circularly polarized implantable angular ring antenna", IEEE Transactions on Antennas and Propagation, DOI 10.1109/LAWP.2017.2734246.

[8] Joysmita Chatterjee, Akhilesh Mohan and Vivek dixit, "Broadband Circularly Polarized H-shaped patch antenna using reactive impedance surface.", IEEE Transactions on Antennas and Propagation, DOI 10.1109/LAWP.2018.2806993.

[9] Y. Dong, H. Toyao and T. Itoh, "Compact circularlypolarized patch antenna loaded with metamaterial structures," IEEE Trans. Antennas Propag., vol. 59, no. 11, pp. 4329-4333, Nov. 2011.

[10] Y. Liu, S. Chen, Y. Ren, J. Cheng, and Q. H. Liu, "A broadband proximity-coupled dual-polarized microstrip antenna with L-shape backed cavity for X-band applications," AEU-Int. J. Electron. Commun., vol. 69, no. 9, pp. 1226-1232, Sep. 2015.

[11] C. Deng, Y. Li, Z. Zhang, G. Pan, and Z. Feng, "Dual-band circularly polarized rotated patch antenna with a parasitic circular patch loading," IEEE Antennas Wireless Propag. Lett., vol. 12, pp. 492-495, 2013.

[12] C. H. Chen and E. K. N. Yung, "A novel unidirectional dual-band circularly-polarized patch antenna," IEEE Trans.
Antennas Propag., vol. 59, no. 8, pp. 3052-3057, Aug 2011.

[13] A. K. Gautam and B. K. Kanaujia, "A novel dual-band asymmetric slit with defected ground structure microstrip antenna for circular polarization operation," Microw. Opt. Technol. Lett., vol. 55, no. 6, pp. 1198-1201, June 2013.

[14] A. K. Gautam, P. Benjwal, and B. K. Kanaujia, "A compact square microstrip antenna for circular polarization," Microw. Opt. Technol. Lett., vol. 54, no. 4, pp. 897-900, Apr. 2012.

[15] A. K. Gautam, A. Kunwar, and B. K. Kanaujia, "Circularly polarized arrowhead-shape slotted microstrip antenna," IEEE Antennas Wireless Propag. Lett., vol. 13, pp. 471474, 2014.

[16] N. Ojaroudi, M. Ojaroudi, and N. Ghadimi, "Dual bandnotched small monopole antenna with novel W-shaped conductor backed-plane and novel T-shaped slot for UWB applications," IET Microwaves, Antennas \& Propagation, vol. 7, pp. 8-14, 2013.

[17] Bao, X.L., and Ammann, M.J.: 'Wideband dual-frequency dual polarized dipole-like antenna', IEEE Antennas Wirel. Propag. Lett., 2011,10, pp. 831-834. 